David Stadelmann ${ }^{1,3}$ / Marco Portmann ${ }^{2,3}$ / Reiner Eichenberger ${ }^{2,3}$

\title{
How Lobbying Affects Representation: Results for Majority-Elected Politicians
}

\author{
${ }^{1}$ University of Bayreuth, Universitätsstraße 30, 95440 Bayreuth, Germany, E-mail: david.stadelmann@uni-bayreuth.de \\ ${ }^{2}$ University of Fribourg, Bd. de Pérolles 90, 1700 Fribourg, Switzerland, E-mail: marco.portmann@unifr.ch, \\ reiner.eichenberger@unifr.ch \\ ${ }^{3}$ CREMA - Center for Research in Economics, Management and the Arts, Zurich, Switzerland, E-mail: \\ david.stadelmann@uni-bayreuth.de,marco.portmann@unifr.ch, reiner.eichenberger@unifr.ch
}

\begin{abstract}
:
While most observers feel that interest groups influence parliamentary decisions, direct evidence on this topic is scarce. Matching parliamentary votes with referendum results helps to bridge this gap. Existing research for politicians of the Swiss Lower House of Parliament suggests that the number of sectional and cause interest groups affect the quality of political representation. We extend this analysis to majority-elected politicians of the Upper House and by more than 50 referendum decisions for the Lower House. Our results show that the pure number of sectional or cause groups does not affect defection of politicians from their constituents which suggests that the generalizability of the results may be limited.
\end{abstract}

Keywords: interest groups, representation, referenda, MP defection, electoral systems

JEL classification: D70, H30

DOI: 10.1515/bejeap-2016-0040

\section{Introduction}

The idea that interest groups affect political representation is an old one. A major difficulty of empirical studies on political representation is to elicit constituents' preferences on legislative proposals and confront them with decisions by political representatives (see, among others, Gerber \& Lewis 2004; Golder \& Stramski 2010; Lott \& Davis 1992; Matsusaka 2010). A way out of this dilemma is to assess the impact of interest groups on political representation by comparing referendum results in Switzerland with legislative decisions made by members of the parliament (MPs). Swiss constituents regularly reveal their preferences for different policies by voting in referenda (see Frey 1994; Hessami 2016). The preferences of the majority of constituents can be confronted with identically-worded decisions by MPs from the same constituencies to obtain a direct measure of political congruence (or inversely defection) as discussed in Portmann, Stadelmann, and Eichenberger (2012). ${ }^{1}$ This type of analysis is also successfully pursued by Giger and Klüver (2016) (henceforth GK) who assess the influence of different types of interest groups on members of the proportionally-elected Lower House of Parliament. GK employ our original measure of defection and distinguish two types of interest groups, i. e. sectional and cause groups (see Klüver 2012). Their results suggest that MPs with ties to more sectional groups have a higher probability to defect from the majority of their constituents, while having affiliations with cause groups fosters congruence between MPs and their constituents. GK's innovation is to analyze differences between different types of interest groups. Their analysis is an important step forward compared to existing literature on MP defection which only analyzed the total number of interest groups (see Portmann, Stadelmann \& Eichenberger 2012).

However, GK focus only on proportionally-elected politicians. The employed measure of MP defection is, however, fundamentally majoritarian as it confronts the decisions of individual MPs with the preferences of the majority of constituents. We extend the analysis of GK by employing a new dataset on politicians from the Swiss Upper House of Parliament and measure MP defection in the identical way. A major difference between the two houses is the electoral system: MPs from the Lower House are elected in a proportional system (see GK, p. 194) while MPs of the Upper House are elected under a majoritarian system. It is well known that electoral systems affect the way individual politicians represent their constituents' preferences and who is blamed for defection (see, among others, Cox 1990; Powell 2009; Stadelmann, Portmann \& Eichenberger 2013). It can be expected that majority-elected politicians face pressure to represent the electoral center independently of the 
types of interest groups with which they are affiliated as they need to appease the majority of their constituents. Proportionally-elected politicians, on the other hand, have more leeway to cater for different interests at the margins of the electoral spectrum such that different interest groups may yield an influence. We confront MP's parliamentary votes from the Upper House with referendum outcomes on identical issues and analyze whether sectional and cause groups affect MP defection.

Our results show that neither the number of sectional nor cause groups explain defection of majority-elected politicians from their constituents' preferences at statistically significant levels. Point estimates suggest a close to zero impact of both types of interest groups on MP defection. This pattern even holds when using the identical dataset as GK for proportionally-elected politicians but focusing on MPs from districts with one or two seats, who are, in fact, elected by close to majority vote. ${ }^{2}$ These results point to potential limits of the generalizability of GK's findings and we offer a brief discussion why different results may emerge. Given GK's findings for proportionally-elected MPs and our evidence for majority-elected MPs, we interpret the existing evidence so far as suggestive that the institutional setting, and, in particular, the electoral system, ${ }^{3}$ may have the potential to moderate the role interest groups play for political representation.

\section{Parliamentary Votes, Referenda and Interest Groups}

We assess the impact of interest groups on political representation by employing the same approach to classify sectional and cause groups as GK, and we combine legislative votes cast by MPs with voter preferences from Swiss referenda (as in earlier contributions by Portmann, Stadelmann \& Eichenberger 2012; Stadelmann, Portmann \& Eichenberger 2013; Stadelmann, Portmann \& Eichenberger 2013). However, we do not exclusively focus on proportionally-elected MPs but employ a new dataset for majority-elected MPs.

Switzerland offers an ideal setting for investigating how interest groups shape the relationship between voters and politicians. First, Swiss MPs have to disclose all their interest affiliations in a public register which is easily accessible and often referred to in media reports. Second, the Swiss practice of submitting measures identical to those voted on by MPs to referenda allows comparing the behavior of constituents and their MPs on exactly the same issues. Referenda permit constituents to judge different policies and rank them against the status quo. Matching MP votes with referendum outcomes yields analytical leverage as instances in which MPs voted contrary to the constituent preferences can be identified. ${ }^{4}$

The Swiss Parliament is made up of two houses, the Nationalrat which can be looked at as the Lower House (analyzed in the study by GK) and the Ständerat which is the Upper House Upper House (analyzed in this study). The Lower House has 200 members who are elected under a proportional system. The Upper House has 46 members elected under a majoritarian system in the same electoral districts as MPs from the Lower House. ${ }^{5}$ Both Houses have identical power in the legislative process, i. e. proposals have to pass both Houses to be adopted and the formal requirements and prerogatives to be elected in the two Houses are identical, apart from the electoral system (see Stadelmann, Portmann \& Eichenberger 2013).

While final votes in the Lower House are recorded by an electronic voting system, such a system has only been installed in the Upper House in spring 2014. MPs in the Upper House simply held up their hands which were then counted by two tellers. Since winter 2006, however, a camera records the sessions of the Upper House and video streams are available on the internet such that voting behavior of MPs can be identified as it is observable on the video recording. We have collected and analyzed the video streams since the installation of the camera and thereby identify MP voting behavior in 1,963 cases for 57 different final votes which were subsequently presented to constituents in referenda between 2008 and 2014.

Defection of an MP is measured by a dichotomous variable and occurs if the MP voted in the Upper House differently to the majority of her constituents. This way of measuring defection is identical to how GK measure MP defection. We identify the interest affiliations from the official register for all MPs and we classify their affiliation the same way as GK into sectional and cause groups.

\section{Research design and results}

Our research design is straightforward and comparable to GK: We explain defection of MPs from the majority of their constituents in Table 1. Defection is explained by the number of sectional and cause interest groups. To give interest groups the best chance to exert an impact on defection, we start with a non-stringent setting in Model (1), include additional controls in Models (2) to (4) and finally estimate a conservative full control, canton, party, and referendum consistent fixed-effects setting in Model (5). 


\subsection{Interest Groups Do Not Explain MP Defection}

Results of Model (1) are from a multi-level logistic regression with random-effects for cantons (electoral districts) and parties as employed by GK but for the Upper House instead of the Lower House. We do not include any other variables apart from controls for referendum type (obligatory referendum, facultative referendum, and initiative as the omitted category).

Table 1: The effect of lobbying on defection of MPs in the upper house.

\begin{tabular}{|c|c|c|c|c|c|}
\hline \multicolumn{6}{|l|}{ DV: MP defection } \\
\hline \multicolumn{6}{|l|}{$\begin{array}{l}\text { Explanatory } \\
\text { variables }\end{array}$} \\
\hline \multirow{2}{*}{$\begin{array}{l}\text { No. of sectional } \\
\text { groups }\end{array}$} & 0.004 & 0.005 & 0.013 & 0.012 & 0.010 \\
\hline & $(0.011)$ & $(0.012)$ & $(0.014)$ & $(0.015)$ & $(0.017)$ \\
\hline \multirow[t]{2}{*}{ No. of cause groups } & 0.0001 & 0.005 & 0.002 & 0.002 & -0.002 \\
\hline & $(0.015)$ & $(0.015)$ & $(0.020)$ & $(0.021)$ & $(0.025)$ \\
\hline \multirow{2}{*}{$\begin{array}{l}\text { Official party } \\
\text { position congruence }\end{array}$} & & $-0.856^{*}$ & & $-0.931^{*}$ & $-0.786^{*}$ \\
\hline & & $(0.152)$ & & $(0.160)$ & $(0.196)$ \\
\hline \multirow{2}{*}{$\begin{array}{l}\text { Closeness of } \\
\text { referendum }\end{array}$} & & $5.092^{*}$ & & $5.204^{*}$ & \\
\hline & & $(0.653)$ & & $(0.662)$ & \\
\hline \multirow{2}{*}{$\begin{array}{l}\text { Closeness of } \\
\text { parliamentary } \\
\text { decision }\end{array}$} & & -0.363 & & -0.351 & \\
\hline & & $(0.453)$ & & $(0.459)$ & \\
\hline \multirow{2}{*}{$\begin{array}{l}\text { No. of months until } \\
\text { next election }\end{array}$} & & 0.002 & & 0.002 & \\
\hline & & $(0.004)$ & & $(0.004)$ & \\
\hline \multirow{2}{*}{$\begin{array}{l}\text { Obligatory } \\
\text { referendum }\end{array}$} & $-1.335^{*}$ & $-1.242^{*}$ & $-1.358^{*}$ & $-1.276^{*}$ & \\
\hline & $(0.198)$ & $(0.211)$ & $(0.199)$ & $(0.213)$ & \\
\hline \multirow{2}{*}{$\begin{array}{l}\text { Facultative } \\
\text { referendum }\end{array}$} & 0.119 & -0.041 & 0.120 & -0.049 & \\
\hline & & $(0.111)$ & $(0.118)$ & $(0.113)$ & $(0.120)$ \\
\hline Constant & $\begin{array}{l}-0.812^{*} \\
(0.122)\end{array}$ & $\begin{array}{l}0.423^{* * *} \\
(0.221)\end{array}$ & $\begin{array}{l}-0.967 \\
(0.596)\end{array}$ & $\begin{array}{l}0.572 \\
(0.644)\end{array}$ & $\begin{array}{l}2.346^{* *} \\
(0.964)\end{array}$ \\
\hline \multicolumn{6}{|l|}{ Random effects } \\
\hline $\begin{array}{l}\text { Canton-level } \\
\text { variance }\end{array}$ & 0.001 & 0.002 & & & \\
\hline \multicolumn{6}{|l|}{ Fixed effects } \\
\hline Canton fixed-effects & No & No & Yes & Yes & Yes \\
\hline Party fixed-effects & No & No & Yes & Yes & Yes \\
\hline \multicolumn{5}{|l|}{ fixed-effects } & Yes \\
\hline Model fit & & & & & \\
\hline$N$ & 1963 & 1963 & 1963 & 1963 & 1963 \\
\hline Log likelihood & -1135.879 & -1089.089 & & & \\
\hline AIC & 2285.758 & 2200.179 & & & \\
\hline BIC & 2324.834 & 2261.583 & & & \\
\hline Pseudo $R^{2}$ & & & 0.078 & 0.144 & 0.408 \\
\hline Chi-square & & & $\begin{array}{l}110.311^{*} \\
(\mathrm{df}=36)\end{array}$ & $\begin{array}{l}207.033^{*} \\
(\mathrm{df}=40)\end{array}$ & $\begin{array}{l}657.063^{*} \\
(\mathrm{df}=87)\end{array}$ \\
\hline
\end{tabular}

${ }^{*} p<0.01$

$* * p<0.05$

${ }^{* * *} p<0.1$ Logit coefficients are reported, with standard errors in parentheses. Results of Models 1 and 2 are from a cross-classified multilevel logistic regression glmer function in $R$. Results of Model 3, 4 and 4 are from consistent fixed-effects logistic regressions.

Model (1) reveals that sectional and cause interest groups do not affect the extent of defection of majorityelected MPs. Point estimates are insignificant and close to zero. ${ }^{6}$ Model (2) controls for additional variables. ${ }^{7}$ 
Again, sectional and cause groups do not explain any defection of MPs from their constituents at statistically significant levels. In contrast to the negative effect of cause groups on defection of MPs of the Lower House shown by GK, we observe, if anything, twice a positive sign for sectional and cause groups on defection.

From a statistical point of view, party and canton fixed-effects estimations correspond to a more stringent test than random-effects estimations. Fixed-effects estimations do not require assumptions regarding the expected value of the coefficients for the fixed-effects and such estimations are consistent even if the true model is a random-effects model (see Cameron \& Trivedi 2005). We take account of party and canton fixed-effects in Model (3) and Model (4). Again, neither sectional nor cause interest groups have any explanatory power on defection. Point estimates are close to zero and relatively precise. The difference between the coefficients for section and cause interest groups is not statistically significant. Calculating the discrete effect for doubling the median number of sectional groups (from 3 to 6 groups) and the median number of cause groups (from 3 to 6 ) yields twice a small positive but statistically insignificant change in the probability to defect of $+0.785 \%$-points and $+0.126 \%$-points, respectively. Adding one additional sectional group or one additional cause groups, increases defection by merely $+0.261 \%$-points and $+0.041 \%$-points .

Finally, we include referendum fixed-effects in Model (5). This insures that neither differences between cantons, parties or referenda bias our coefficients of interest for sectional and cause interest groups. In particular, referendum fixed-effects take account of all differences between referenda such as salience, closeness, referendum types, etc. such that these controls and other potentially unobserved variables are fully accounted for which is a major advantage of fixed-effects settings. We find, once again, no statistically significant and quantitatively relevant effect of interest groups on MP defection. Thus, sectional or cause interest groups do not seem to affect political representation for a sample of majority-elected politicians which points to a potential limitation regarding the generalizability of GK's findings.

\subsection{Refinements and Further Tests}

In Table 2, we refine our analysis and provide further evidence that defection of majority-elected MPs is not explained by the number of their interest group affiliations, be it sectional or cause groups.

While GK's idea to distinguish sectional and cause interest groups is appealing, it is comparatively new for economists and in public discussions, such a distinction is rarely made. Prior to GK's analyses, results by Portmann, Stadelmann, and Eichenberger (2012) for proportionally-elected politicians indicated a negative effect of the total number of interest groups on defection. Models (1) and (2) show that the total number of interest groups does not explain MP defection in the Upper House, i. e. the majority-elected politicians with more interest groups in general do neither deviate more nor less from their constituents.

District sizes vary in Switzerland between 1 and 34. Depending on population size, there are eight districts with one or two MPs in the Lower House. For MPs from these districts, electoral incentives are comparable to majority-elected MPs in the Upper House (see the discussion in GK's conclusion, p. 202). In Model (3) we employ the identical dataset as used by GK, but focus on a subset of districts with one or two seats, i. e. we focus on MPs in the GK dataset who are in fact majority-elected. Results indicate that interest groups do not explain defection from the majority's preferences any more for this subsample. In Model (4) we restrict the GK dataset to cantons with more than two representatives, i. e. on these MPs who are elected proportionally, we reestablish GK's quantitative and qualitative results.

Table 2: Refinements and further tests.

\begin{tabular}{|c|c|c|c|c|c|c|}
\hline DV: MP defection & Model 1 & Model 2 & $\begin{array}{l}\text { Model } 3 \\
\text { (GK) }\end{array}$ & $\begin{array}{l}\text { Model } 4 \\
\text { (GK) }\end{array}$ & Model 5 & $\begin{array}{l}\text { Model } 6 \\
\text { (GK) }\end{array}$ \\
\hline Sample analyzed & $\begin{array}{l}\text { all Upper } \\
\text { House }\end{array}$ & $\begin{array}{l}\text { all Upper } \\
\text { House }\end{array}$ & $\begin{array}{l}1 \text { or } 2 \text { seats } \\
\text { Lower } \\
\text { House }\end{array}$ & $\begin{array}{l}>2 \text { seats } \\
\text { Lower } \\
\text { House }\end{array}$ & $\begin{array}{l}\text { all Upper } \\
\text { House }\end{array}$ & $\begin{array}{l}1 \text { or } 2 \text { seats } \\
\text { Lower } \\
\text { House }\end{array}$ \\
\hline $\begin{array}{l}\text { Explanatory variables } \\
\text { No. of all groups }\end{array}$ & $0.003(0.009)$ & $0.009(0.014)$ & & & & \\
\hline No. of sectional groups & & & $\begin{array}{l}-0.010 \\
(0.016)\end{array}$ & $\begin{array}{l}0.014^{* *} \\
(0.006)\end{array}$ & $0.012(0.018)$ & $\begin{array}{l}-0.004 \\
(0.016)\end{array}$ \\
\hline No. of cause groups & & & $\begin{array}{l}-0.069 \\
(0.065)\end{array}$ & $\begin{array}{l}-0.033^{*} \\
(0.009)\end{array}$ & $0.001(0.025)$ & $\begin{array}{l}-0.029 \\
(0.069)\end{array}$ \\
\hline $\begin{array}{l}\text { No. of sectional groups } \\
\text { (Party) } \\
\text { No. of cause groups } \\
\text { (Party) }\end{array}$ & & & & & $\begin{array}{l}-0.004 \\
(0.007) \\
-0.008 \\
(0.009)\end{array}$ & $\begin{array}{l}-0.0004 \\
(0.003) \\
-0.005 \\
(0.003)\end{array}$ \\
\hline & & & & \multicolumn{3}{|c|}{$\begin{array}{r}\text { Brought to you by | Universitaetsbibliothek Basel } \\
\text { Authenticated } \\
\text { Download Date | 4/29/19 4:16 PM }\end{array}$} \\
\hline
\end{tabular}




\begin{tabular}{|c|c|c|c|c|c|c|}
\hline $\begin{array}{l}\text { Other controls } \\
\text { Random effects }\end{array}$ & Yes & Yes & Yes & Yes & Yes & Yes \\
\hline Canton-level variance & 0.0001 & & 0.040 & 0.212 & & 0.033 \\
\hline $\begin{array}{l}\text { Party-level variance } \\
\text { Fixed effects }\end{array}$ & 0.022 & & 0.126 & 0.021 & & 0.207 \\
\hline Canton fixed-effects & No & Yes & No & No & Yes & No \\
\hline Party fixed-effects & No & Yes & No & No & Yes & No \\
\hline $\begin{array}{l}\text { Referendum } \\
\text { fixed-effects }\end{array}$ & No & Yes & No & No & Yes & No \\
\hline Model fit & & & & & & \\
\hline $\begin{array}{l}N \\
\text { Log likelihood }\end{array}$ & $\begin{array}{l}1963 \\
-1135.86\end{array}$ & 1963 & $\begin{array}{l}1078 \\
-586.057\end{array}$ & $\begin{array}{l}19182 \\
-10983.57\end{array}$ & 1963 & $\begin{array}{l}1078 \\
-583.86\end{array}$ \\
\hline $\mathrm{AIC}$ & 2283.721 & & 1196.114 & 21993.15 & & 1197.72 \\
\hline BIC & 2317.214 & & 1255.909 & 22095.35 & & 1272.463 \\
\hline $\begin{array}{l}\text { Pseudo } R^{2} \\
\text { Chi-square }\end{array}$ & & $\begin{array}{l}0.408 \\
657.2^{*}(\mathrm{df}= \\
86)\end{array}$ & & & $\begin{array}{l}0.409 \\
659.1^{*}(\mathrm{df}= \\
89)\end{array}$ & \\
\hline
\end{tabular}

${ }^{*} p<0.01 ;$
$* * \quad p<0.05 ;$

$* * p<0.05$

Logit coefficients are reported, with standard errors in parentheses. Results of Model 1, 3, 4 and 6 are from a cross-classified multilevel logistic regression glmer function in $R$. Results of Model 2 and 5 are from consistent fixed-effects logistic regressions. "Other controls" include the same set as in Table 1 and the number of MPs per canton in Models (4) and (6).

GK introduced in some of their analyses the aggregate number of interest groups per party, i. e. they introduce two new variables for each individual politician which reflect the sum of all sectional and cause interest groups of politicians from their parties. These variables are the same for all MPs with the same party affiliation and politicians from larger parties have more interest groups by construction. This makes the interpretation of these variables difficult in regressions because the number of interest groups at the party level also changes as the number of politicians increases. Nevertheless, for the sake of completeness, we follow their approach in Model (5) for MPs of the Upper House and Model (6) for MPs of the Lower House from cantons with one or two seats. We do not observe any significant or quantitatively relevant effect of the number of sectional or cause groups of MPs or their parties on defection.

\subsection{Interpreting Differences Between the Analyses}

GK suggest that being affiliated with more sectional (cause) interest groups leads to more (less) defection of proportionally-elected politicians while we observe zero effects for sectional as well as cause interest groups for majority-elected politicians. We believe that the existing results can be interpreted as suggestive evidence that the centripetal forces of a majoritarian system render the influence of interest groups less relevant. However, different results may also be due to a different (self-) selection of politicians into the houses. Moreover, our main result for majority-elected politicians in Table 1 is based on fewer observations due to a lower number of referenda and a lower number of politicians in the Upper House than GK's original results. We also analyze a more recent time period (2008 to 2014 instead of 1996 to 2009). Finally, we employ GK's concept to categorize sectional and cause interest groups and while the dichotomous classification is mostly straightforward classification issues arise in some instances such as for trusts or pension funds. ${ }^{8}$

We can rule out the third and fourth point as sources for differences by employing GK's dataset but restrict it to MPs from districts with only one or two seats, as proportional representation with district magnitude of one and two comes close to majority elections.

We have also categorized interest groups affiliated with proportionally elected-politicians from the Lower House for the full sample from 1996 to 2014 and extend thereby the original GK dataset by six years or about a third in terms of referenda (see Online Appendix). We reconfirm for this extended sample the negative effect of cause groups on defection and a positive, though statistically insignificant, effect of sectional groups on MP defection in the Lower House. Restricting the sample to MPs from the Lower House and the time frame that can be analyzed for the Upper House (2008-2014) we find that all coefficients for MPs from the Lower House exhibit the same sign as in GK, though they are slightly smaller and statistically insignificant (see Online Appendix). ${ }^{9}$ 


\section{Conclusions and future research recommendations}

In their inspiring contribution, GK show that MPs with more ties to sectional interest groups exhibit a higher defection from voters, while having more ties to cause interest groups decreases defection. Defection is measured as incongruence between MPs' roll call votes and their constituents' majority decisions in referenda on identical legislative proposals. Whereas GK's analysis is based on proportionally-elected politicians, we extend it to new data for majority-elected MPs employing otherwise an identical approach.

Our results show that the number of interest groups, whether sectional or cause groups, do not explain defection of majority-elected MPs from their constituents. Given the existing evidence in the literature and our new results, we speculate that differences in the relative strength of centrifugal and centripetal forces in proportional vs majoritarian system contribute to moderating the effect of interest groups on MP defection. Thereby, we point to a potentially important factor which may limit the generalizability of GK's findings.

GK's results together with our extension open new avenues for research. Further theoretical analyses on the interaction between electoral systems and the influence of interest groups seem promising. The relationship between parties and interest groups also needs to be explored as differences between proportional and majoritarian systems shape the effect that parties have on representation. Finally, we hope that future studies for other countries, different electoral systems and different institutional settings where interest group influence can be explored will stimulate further comparative research on this topic.

\section{Acknowledgement}

We thank Marcus Drometer, Thomas Groll, and all the participants of the 2015 Annual Congress of the International Institute of Public Finance in Dublin for helpful and encouraging comments.

\section{Notes}

${ }^{1}$ Comparing referendum and MPs' decisions in general is also recommended and performed in Stadelmann et al. (2012, 2013) or Brunner, Ross, and Washington (2013) as a new approach to measure congruence.

${ }^{2}$ Re-estimating GK with an extended dataset for proportionally-elected politicians in an online appendix, we tend to confirm their original results although they lose statistical significance for sectional interest groups.

${ }^{3}$ Effects of institutions and electoral systems as well as the moderating role of party discipline are discussed in Fredriksson and Wollscheid (2014) or Stadelmann, Portmann, and Eichenberger (2013).

${ }^{4}$ Such direct measures of MP defection are usually not available and the literature tends to rely on proxies, surveys or other indirect ways to measure defection, rent-seeking or illicit behavior of politicians (see, e. g., Bender and Lott 1996; for an early discussion or more recently Ågren, Dahlberg \& Mörk 2007; Ruske 2015; or Kauder and Potrafke 2016).

${ }^{5}$ Exceptions are the Canton of Jura and since the end of 2011 the Canton of Neuchâtel that apply a proportional system for their two members. Omitting them does not change the results.

${ }^{6}$ If we do not control for referendum types and if we do not account for random-effects for cantons and parties, the same results emerge: Interest groups do not affect defection of majority-elected MPs.

${ }^{7}$ We do not include variables such as "No. of MPs per canton" into the estimation because they are only relevant for the proportionallyelected MPs analyzed by GK but not so for the majority-elected MPs from the Upper House analyzed here.

${ }^{8}$ Employing the GK's data but restricting their sample to districts with only one or two seats yields no significant results for both types of interest groups (Table 2, Model 3 and 6). While the employed subset represents a fraction of the total number of observations, we analyze in all our models more than 1,000 observations which should allow for robust statistical inference.

${ }^{9}$ The effects of the number of sectional and cause groups at the party level remain statistically significant. Note again that the effect of the number of groups at the party level is difficult to interpret as individual politicians are analyzed.

\section{References}

Bender, B., and J. R. Lott. 1996. “Legislator Voting and Shirking: A Critical Review of the Literature.” Public Choice 87 (1-2): 67-100.

Brunner, E. J., S. L. Ross, and E. L. Washington. 2013. “Does Less Income Mean Less Representation?” American Economic Journal: Economic Policy $5(2): 53-76$.

Cameron, A. C., and P. K. Trivedi. 2005. Microeconometrics - Methods and Applications. New York: Cambridge University Press.

Cox, G. W. 1990. “Centripetal and Centrifugal Incentives in Electoral Systems.” American Journal of Political Science 34 (4): $903-935$.

Fredriksson, P. G., and J. R. Wollscheid. 2014. “Political Institutions, Political Careers and Environmental Policy.” Kyklos 67 (1): 54-73.

Frey, B. S 1994. “Direct Democracy: Politico-Economic Lessons from Swiss Experience.” American Economic Review 84 (2): 338-342.

Gerber, E. R., and J. B. Lewis. 2004. “Beyond the Median: Voter Preferences, District Heterogeneity, and Political Representation." Journal of

Political Economy 112 (6): 1364-1383. 
Giger, N., and H. Klüver. 2016. “Voting against Your Constituents? How Lobbying Affects Representation." American Journal of Political Science 60 (1): 190-205.

Colder, M., and J. Stramski. 2010. “Ideological Congruence and Electoral Institutions.” American Journal of Political Science 54 (1): 90-106.

Ågren, H., M. Dahlberg, and E. Mörk. 2007. “Do Politicians' Preferences Correspond to Those of the Voters? An Investigation of Political Representation." Public Choice 130 (1/2): 137-162.

Hessami, Z. 2016. "How Do Voters React to Complex Choices in a Direct Democracy? Evidence from Switzerland." Kyklos 69 (2): $263-293$.

Kauder, B., and N. Potrafke. 2016. "Supermajorities and Political Rent Extraction." Kyklos 69 (1): 65-81.

Klüver, H. 2012. “Biasing Politics? Interest Group Participation in EU Policy-Making." West European Politics 35 (5): 1114-1133.

Lott, J. R., and M. L. Davis. 1992. “A Critical Review and an Extension of the Political Shirking Literature.” Public Choice 74 (4): $461-484$

Matsusaka, J. G. 2010. “Popular Control of Public Policy: A Quantitative Approach." Quarterly Journal of Political Science 5 (2): 133-167.

Portmann, M., D. Stadelmann, and R. Eichenberger. 2012. “District Magnitude and Representation of the Majority's Preferences: QuasiExperimental Evidence from Popular and Parliamentary Votes." Public Choice 151 (3-4): 585-610.

Powell, G. B. 2009. "The Ideological Congruence Controversy: The Impact of Alternative Measures, Data, and Time Periods on the Effects of Election Rules." Comparative Political Studies 42 (12): 1475-1497.

Ruske, R 2015. “Does Economics Make Politicians Corrupt? Empirical Evidence from the United States Congress.” Kyklos 68 (2): $240-254$.

Stadelmann, D., M. Portmann, and R. Eichenberger. 2012. “Evaluating the median voter model's explanatory power." Economics Letters 114: 312-314.

Stadelmann, D., M. Portmann, and R. Eichenberger. 2013. “Quantifying Parliamentary Representation of Constituents” Preferences with Quasi-Experimental Data." Journal of Comparative Economics 41 (1): 170-180.

Stadelmann, D., M. Portmann, and R. Eichenberger. 2016. "Preference Representation and the Influence of Political Parties in Majoritarian Vs. Proportional Systems: An Empirical Test." British Journal of Political Science. 